BMJ Nutrition,

Prevention \& Health

\title{
Responsibility for vitamin D supplementation of elderly care home residents in England: falling through the gap between medicine and food
}

Joseph Williams, ${ }^{1}$ Carol Williams (1) ${ }^{2}$

To cite: Williams J, Williams C. Responsibility for vitamin $\mathrm{D}$ supplementation of elderly care home residents in England: falling through the gap between medicine and food. BMJ Nutrition, Prevention \& Health 2020;3:e000129. doi:10.1136/ bmjnph-2020-000129

${ }^{1}$ Department of Medical Education, Brighton and Sussex Medical School, Brighton, UK ${ }^{2}$ School of Health Sciences, University of Brighton, Brighton, UK

\section{Correspondence to}

Ms Carol Williams, School of Health Sciences, University of Brighton, Brighton BN1 9PH, UK; c.williams2@brighton.ac.uk

Received 21 June 2020 Revised 16 August 2020 Accepted 17 August 2020 Published Online First 12 October 2020
Check for updates

(C) Author(s) (or their employer(s)) 2020. Re-use permitted under CC BY-NC. No commercial re-use. See rights and permissions. Published by BMJ.

\section{ABSTRACT}

Introduction Daily vitamin D supplements are recommended for elderly care home residents; however, they are rarely given and vitamin $\mathrm{D}$ deficiency in care homes is widespread. This study aimed to understand the determinants of current practice and perceived responsibility for the vitamin $D$ status of residents. Methods Thirteen semi-structured interviews were conducted with key informants in two areas of Southern England including care home managers, general practitioners (GPs) and public health professionals. Interviews were audio recorded and transcribed verbatim. Results Inductive thematic analysis identified four themes: framing of vitamin D supplements as medicines; professional and sector boundaries whereby GPs are perceived as responsible for the vitamin D status of residents and care home managers felt unable to administer over-the-counter vitamin tablets; low awareness of national guidance; and ethical and practical issues. This results in vitamin D supplements requiring prescription by medical professionals and few residents receiving them.

Conclusion The medical framing of vitamin D supplements in care homes is a practical barrier to implementation of longstanding nutrition guidelines. A paradigm shift is needed so that vitamin $D$ is understood as a protective nutrient as well as a medicine, and a public health as well as a medical responsibility. Vitamin D is important for musculoskeletal health. Possible links with COVID-19 are still being investigated. The pandemic has drawn attention to conditions in care homes and there is an opportunity to revise current guidance on vitamin D supplementation which will have lasting benefit for this vulnerable group.

\section{INTRODUCTION}

Public health is classically defined as "the art and science of preventing disease, prolonging life and promoting health through the organised efforts of society". ${ }^{1}$ Arguably societies organise themselves more readily to improve the health of those in view. Those out of sight, including older adults in residential care settings, can often be forgotten. The coronavirus (COVID-19) pandemic has

\section{What this paper adds}

- This study suggests that the vitamin D status of elderly care home residents is perceived as the responsibility of GPs, and care home staff would feel vulnerable to suggestions of malpractice in administering over-the-counter vitamin D supplements.

- Vitamin D supplements are regulated as foods. This study found that in the elderly residential care sector they are framed as medicines and only given when prescribed. Their limited use puts residents at risk of vitamin D deficiency and poor musculoskeletal health.

- Nutrition recommendations for vitamin D supplementation rely on personal responsibility: this is not effective in a population constrained by institutional living. A review of guidelines and regulations in England is required to establish responsibility for implementing public health recommendations on vitamin D supplementation in elderly residential care homes.

brought the health and vulnerability of those in elderly care homes to the fore. ${ }^{2}$ Vitamin $\mathrm{D}$ has also received attention due to possible links with COVID-19. ${ }^{34}$ Our investigation into how vitamin $\mathrm{D}$ nutrition supplementation is addressed in care homes reveals both a failure to implement evidence-based recommendations and a social injustice in urgent need of public health advocacy and resolution.

Vitamin D is a prohormone rather than a nutrient and the main source is endogenous synthesis in the skin. Synthesis occurs when skin is exposed to ultraviolet B (UVB) radiation in sunlight. In winter months at latitudes with shorter day lengths, the UVB is insufficient due to the low angle of the sun, thus vitamin $\mathrm{D}$ deficiency can be viewed as sunshine deficiency. ${ }^{35}$ There are few significant food sources and it is usually not possible to meet vitamin D needs from diet alone. ${ }^{6}$

Vitamin D is required for the regulation of calcium and phosphorus metabolism and 
there is strong evidence that insufficient vitamin D affects musculoskeletal health and development. ${ }^{7}$ Vitamin D has also been cited as having a potential role in numerous other aspects of health, including immunity, cardiovascular health, neurological conditions, respiratory infections, lung function and cancer. ${ }^{7}$ Most recently, there has been interest in the potential role of vitamin $\mathrm{D}$ status in the susceptibility to COVID-19 and the striking overlap between risk factors for severe COVID-19 and vitamin D deficiency. ${ }^{4-10}$ Older people and Black, Asian and minority ethnic groups are at increased risk of vitamin D insufficiency due to spending less time outside, covering their skin, or having darker skin which needs longer exposure for synthesis to occur. ${ }^{611}$ Rapid reviews in the UK concluded that there was currently insufficient evidence to support taking vitamin D supplements to prevent or treat COVID-19, but reiterated recommendations made in April 2020 advising everyone to consider taking 400 IU $(10 \mu \mathrm{g})$ of vitamin D a day if they were indoors most of the day due to COVID-19 lockdown measures. ${ }^{12-14}$

Elderly residents in residential care homes/nursing homes (hereafter referred to as care homes), particularly those with limited mobility, are likely to spend more time indoors and have limited sun exposure. For nearly 30 years they have been recognised in the UK as a group vulnerable to vitamin $\mathrm{D}$ deficiency and requiring routine supplementation without pre-screening.$^{71516}$ In 2016 , recommendations for daily vitamin $\mathrm{D}$ supplements were extended to the entire population in the winter months, and throughout the year for those living in care homes. ${ }^{17}$ National bodies from countries around the world have issued similar recommendations for care home residents including Australia, Canada, France, Norway, New Zealand and the USA. ${ }^{1819}$

Despite the decades of recommendations for supplementation in this population, vitamin D deficiency in care home residents is widespread throughout Europe, Asia and the Americas. ${ }^{18}$ Studies in Austria, ${ }^{20}$ Belgium, ${ }^{21}$ Germany $^{22}$ and Sweden ${ }^{23}$ found that almost all residents of care homes were vitamin D deficient. A notable exception is New Zealand where a publicly funded universal vitamin D supplementation programme for care homes has been in operation since 2011. An evaluation in 2014 found that $75 \%$ of care home residents took supplements, and almost all of those receiving the supplements had healthy serum levels of 25-hydroxyvitamin D $(25(\mathrm{OH}) \mathrm{D})$, the marker for vitamin D status. ${ }^{24}$

Whether vitamin supplements are considered as a medicine or a food has significant implications. In most countries vitamin and mineral supplements are regulated and sold as foodstuffs rather than medicines. ${ }^{25-27}$ Supplementation with vitamin D as a food is considered a personal responsibility which, in a care home setting, could be passed on to family members or care home staff. However, if vitamin D supplements are considered as medicines, responsibility is deferred to medical professionals. The duality of vitamin $\mathrm{D}$ as both a medicine and a food is evident in contradictory health and care regulations and guidance in England. Care homes are required to assess resident's nutritional needs and provide food to meet those needs, including "dietary supplements when prescribed by a healthcare professional". ${ }^{28}$ Guidance to NHS clinical commissioning groups expressly advises GPs against routine prescription of vitamins in primary care due to "limited evidence of clinical effectiveness" and because "vitamin D supplements can be bought cheaply and easily". ${ }^{29}$ The guidance makes exceptions for medically diagnosed vitamin D deficiency or for osteoporosis but not for maintenance or preventative treatment.

The aim of this study was to better understand current practice in the implementation of public health guidance on vitamin D supplementation in the care home setting. The purpose was to generate insights which could be used to inform and advocate for a policy and practice review as a first step towards increasing vitamin D supplement uptake and reducing vitamin D deficiency in elderly care home residents.

\section{METHODS}

The research was carried out using a pragmatic interpretive methodology. Semi-structured interviews were used to explore current practice around vitamin D supplementation, perceived responsibility for vitamin D status and supplementation, and barriers to supplementation. Interviews were conducted by telephone with key stakeholders identified as having a role in the care of elderly care home residents. The study used purposive opportunistic sampling to recruit participants, including: senior members of care home staff; general practitioners (GPs); members of local authority public health departments; and other relevant professionals (as identified by participants) with shared constituencies of care home residents. Eligible participants were approached by email and invited to participate. Informed consent was obtained from all participants before commencing the interview. Recruitment was continued until data saturation was reached.

\section{Data collection and analysis}

Interviews were conducted between 22 April 2018 and 31 August 2018, audio recorded and transcribed verbatim. The data were approached inductively using a six-stage process as described by Braun and Clarke. ${ }^{30} \mathrm{JW}$ read and re-read the transcripts for immersion in the data and developed initial codes and themes. All transcripts were independently read and coded by CW, using qualitative data software (NVivo) to support the process. Codes and themes were elaborated using an iterative process, with the two researchers referring back to the raw data to substantiate emerging ideas.

\section{RESULTS}

Thirteen interviews, lasting approximately 15 minutes, were conducted with employees of 13 different 
Table 1 Participant demographics

\begin{tabular}{llll}
\hline Areas & Coding & Position & Organisation \\
\hline A & GP1, GP2 & Two general practitioners & Two general practices \\
& CHM1, CHM2 & Two care home managers & Two care homes \\
\hline B & PubH1 & Senior public health practitioner & Local authority \\
\hline & GP3, GP4 & Two general practitioners & Two general practices \\
& CHM3, CHM4 & Two care home managers & Two care homes \\
& FallSP & Falls specialist practitioner & NHS community trust \\
& EConsP & Consultant elderly care physician & NHS hospital trust \\
& PCDiet & Primary care dietitian & NHS clinical commissioning group \\
& PubH2 & Public health programme manager & Local authority \\
\hline
\end{tabular}

organisations operating in two districts of nonneighbouring areas of South East England. Participant roles and employing organisations are outlined in table 1. Four broad themes and five sub-themes were identified; these are summarised in box 1 and described in detail below.

\section{Vitamin D understood as a medical issue}

All the stakeholders in elderly care we spoke to referred to vitamin $\mathrm{D}$ as something which residents took on an individual basis, usually because it had been prescribed by a GP. None knew of any care home where vitamin D supplements were given routinely to residents as part of a protective public health measure; "So there's no kind of protocol or carpet/universal plan to prescribe vitamin D supplements to patients of ours at care homes" (GP3). GP prescribing was in response to falls or fractures or following diagnosis of vitamin D deficiency or osteoporosis. (Quotations in box 2 illustrate this theme.)

\section{Professional and sector boundaries}

Perceived responsibility and roles

There was a strong agreement, including from the GP participants, that the vitamin D status of elderly care home residents was the responsibility of the GP (see box 3 ). Only the dietitian suggested that perhaps the primary responsibility should lie with the care home since the home had a "responsibility to provide a diet that includes all the nutrients they need" (PCDiet). One of the

\section{Box 1 Summary of themes and sub-themes}

\section{Themes and sub-themes}

1. Medical framing: vitamin D understood as a medical issue

2. Professional and sector boundaries

- Perceived responsibility and roles: authority and vulnerability

- Cost implications: who pays and provides

- Policy, regulations, guidance and compliance

3. Low awareness of recommendations and need for vitamin $D$ supplements.

4. Ethical and practical considerations

- Ethics of consent and life stage

- Resistance to polypharmacy
GPs touched on the issue of medicine versus diet that is central to this subject "... if you're looking at it from a medical point of view, then I, the GP, would be responsible. If you're looking at this from a 'are the patients getting a well-balanced diet that would include vitamin D? ...' I would see that as the home's responsibility" (GP1). Several of the non-medical participants felt the responsibility was shared between the care home and the GP, but here the GP was the decision maker and their role was to alert GPs about individual residents. From the interviews it was clear that there was an implicit hierarchy and deferment to the medical profession which meant care home staff felt they would not be able to make decisions about supplements: "we can only ask the doctor if they will prescribe it" (CHM1). Participants from the medical profession acknowledged and understood why care home staff could feel constrained or vulnerable in this area.

Cost implications—-who pays and provides?

There was considerable ambiguity about who should be responsible for providing and paying for supplements. Again, most participants felt this was a GP responsibility because of their role as prescriber, and any change from this arrangement would have financial consequences for the care home or the residents, as noted in the quotes

\section{Box 2 Representative quotations for theme 1: vitamin D} understood as medical issue

"Quite a lot of the vitamin D stuff that we tend to prescribe is mixed in with calcium as well... Usually that will be in people who are either known to be osteoporotic or may have had a previous low trauma fracture before." (GP1)

"We don't have anything in place in terms of a protocol for specifically checking it with each patient. It tends to come up in those where it's more obvious because of their history. And if we happened to think about it, which probably means missing quite a few patients who (would) benefit from it." (GP2)

"No. Literally since I've been here, there's only been two occasions where residents have gone on to vitamin D. And that's because they've had routine blood tests done, and it's identified their levels were low." (CHM4) 
Box 3 Representative quotations for theme 2:

professional and sector boundaries

Sub theme: perceived responsibility and roles: authority and vulnerability

"I would say it's us as their GPs. I guess. Because we've got all their notes. And while, so some of them are nursing homes and got trained nurses. But some of them aren't, some of them just have carers there, so we wouldn't expect it to have to come from them." (GP2)

"I think its probably meant to be a mix of all of us. But I think it probably falls through the gaps." (GP4)

"I mean, if I go in and, as part of my assessment I find that somebody is no longer going out, their diet's quite poor, they're at risk of falls. I may, I will write to the GP. And may suggest that they consider a supplement." (FallSP)

"It's really, really difficult to know for us because we're only carers, if somebody needs vitamin D or not. How would I know that somebody needs vitamin D?" (CHM3)

"The trouble is we're very highly regulated against... we can't just decide to give people a supplement." (CHM1)

"... if the nurses or care staff are giving out these medications then they run into risks about whether or not they've assessed properly that people should be having them. If then there's going to be any interaction between that over-the-counter medication and the prescribed medications. So, the practicalities of dispensing over-the-counter medications in care homes are very difficult." (PCDiet)

\section{Subtheme: cost implications-who pays and provides?}

"I mean, I don't think necessarily we would expect the types of patients who are in care homes or rest homes to necessarily be purchasing it themselves." (GP3)

"And then of course it takes cost out of the issue for the home and for the individual if I prescribe... But for the whole system as a whole, prescribing vitamin $D$ is a lot more expensive than buying it over the counter." (GP1)

"We're not going to start prescribing supplements for everybody. The cost would be prohibitive." (PCDiet)

\section{Subtheme: policy, regulation, guidance and compliance}

"There's no kind of local practice guidance on that [prescribing vitamin $\mathrm{D}$ to all residents]. So, there's nothing saying, you know, we should or shouldn't be doing it. So, it's just not done. As a blanket. Within our practice... I think if there was guidance to do it then we would probably do it." (GP3)

"How do we get over the concept of people wanting to take something that doesn't have to be prescribed and then we get into a care home or a rest home situation that the system can allow that without putting the home at risk of being accused of doing something wrong. And equally, allowing the individual in the bed to have the right to say 'actually, I want some over-the-counter vitamins'." (GP1)

"If a resident wants to take it privately, then that's fine. They can do it as a homely remedy. For a certain amount of time. But it has to be agreed by the GP if they want to take it on a long-term basis." (CHM1)

in box 3. The theoretical responsibility of individual residents paying for their own over-the-counter (OTC) supplements and the impractical reality of this for residents with mobility or cognitive constraints was acknowledged. One GP participant considered the financial aspects more broadly, contrasting the cost of testing serum vitamin D levels which is far higher than the cost of a year's supply of vitamin D supplements.
Box 4 Representative quotations for theme 3: low awareness of recommendations and need for vitamin D supplements

"I mean some of the patients will be more well than others, and I guess if they're outside getting a bit of sunlight and their diet is pretty good, they wouldn't necessarily need to be on it." (GP2)

"So I would never even think about a resident having vitamin D or why they haven't got vitamin D." (CHM3)

"...the message it's not been very clear, about vitamin D, especially for falls prevention... So, we haven't taken it forward because we're not clear, you know, what the message would be. Is it that every older person should be taking vitamin D?... I'll see one thing saying 'yes' and then another saying 'well, not really'." (PubH2).

\section{Policy guidance and compliance}

Each stakeholder we spoke to was adhering to the regulations and operating guidance for their sector. In the absence of any specific guidance about how to implement public health advice on vitamin D supplementation, these restricted homes to only dispensing vitamin $\mathrm{D}$ on prescription: "If somebody said to us that everybody needs to have vitamin D we would make sure that everybody had vitamin D" (CHM3). Three of the four care homes had a 'homely remedy' policy that can provide a mechanism for care homes to give OTC products to residents. ${ }^{31}$ However, they explained that the GP needs to be involved for the supplementation to continue in the long-term. (Quotations in box 3 illustrate this theme.)

\section{Low awareness of national guidance and need for vitamin D supplements}

Apart from the dietitian, none of the participants seemed familiar with the recommendation that all elderly care home residents should receive vitamin D supplements without the need for pre-assessment, as illustrated by quotes in box 4 . Some participants highlighted the role of diet and sunlight in vitamin D status but seemed unaware that these sources cannot provide adequate levels even for the general population during winter months. Several of the GPs referred to care homes needing to ensure that residents got out into the sun, which could be effective in the summer months, but mobility issues mean this is impractical for many residents.

\section{Ethical and practical considerations}

When asked about universal supplementation, several participants raised ethical issues, both around the population versus the individual approach and the limited ability of some residents to give consent: "We have a lot of people with dementia who can't make that decision for themselves" (CHM1). Others questioned the value of introducing another tablet given the age of residents.

Care home staff are responsible for the administration of medicines and supplements to residents and highlighted practical issues which would be barriers to wider supplement use. This included the number of medicines residents already take and how introducing more 
Box 5 Representative quotations for theme 4: ethical and practical considerations

Sub-theme: ethics of consent and life stage

"To supplement everybody without it being their individual choice. Or you know maybe, they could offer it ... without people having to take it." (GP4)

"I don't know how much difference they make at their age, if I'm being perfectly honest." (CHM2)

Sub-theme: resistance to polypharmacy

"It's OK for a GP to come out and say yes, vitamin D, they need to boost their levels'. It's actually trying to support and encourage the resident to actually understand why they need to take that tablet. Because, as far as they're concerned, they've reached a certain age and have never needed it. So why do they now need it?" (CHM4)

"Also, the other issue with vitamin D supplements. Quite often it comes with the calcium. So, it's normally a calcium and vitamin D supplement... Some older people just don't like taking it... It's not particularly nice. It's chalky." (CHM1)

tablets would add to the pill burden for both residents and staff. Another common point related to the formulation of vitamin $\mathrm{D}$ with calcium and how it was difficult to take and was "one of our most destroyed medicines" (CHM2). (Quotations in box 5 illustrate this theme.)

\section{DISCUSSION}

This study aimed to understand perceived responsibility for the vitamin D status of care home residents and explore factors influencing supplementation practice. The study found an overwhelmingly medical rather than public health conception of vitamin $\mathrm{D}$ by those involved in the welfare of elderly care home residents. This stems from regulatory and professional boundaries which treat vitamin $\mathrm{D}$ as a medicine and denies residents recommended dietary supplements to protect their vitamin D levels. These findings may be used to inform advocacy for policy and practice change in England and other countries where vitamin D supplementation in elderly care homes tends to be by prescription-only.

\section{Medicine or food}

The participants of this study all saw vitamin D supplementation as the responsibility of the GP. This medical framing means care home staff fear overstepping their role and defer to medical professionals to diagnose vitamin $\mathrm{D}$ deficiency or osteoporosis as a medical condition and then prescribe vitamin D as a "medicine" in response. In this respect, both care home staff and GPs are complying with the respective regulations and guidance governing their sector: care home staff to administer supplements only when they are prescribed; and GPs not to prescribe supplements for prevention or maintenance. As a result, few elderly care home residents receive vitamin $\mathrm{D}$ supplements.

The medicalisation of this nutrient is at odds with the UK's nutrition advisory committee Scientific Advisory
Committee on Nutrition (SACN), and other nutrition expert panels, who consider vitamin D supplements, along with natural food sources and fortified foods, as a dietary source. ${ }^{7}$ It is also out of step with public health recommendations which identify a population-wide need for vitamin D. Low awareness of the public health need for supplements is not unique to the elderly residential care sector; others have noted that many health professionals may be not be aware of issues around vitamin $\mathrm{D}$, including synthesis, diet and the importance of supplements. ${ }^{32}$ Furthermore, national guidance on healthy catering for older people in residential care makes a general statement on the need for vitamin $\mathrm{D}$ supplements without addressing how this happens in practice or who is responsible. ${ }^{33}$

Our findings suggest that in the elderly residential care sector, the narrative of vitamin $\mathrm{D}$ as a treatment is at the expense of any parallel narrative of vitamin $\mathrm{D}$ as a protective and preventative public health measure. Regulations and guidance must ensure both approaches are permitted. In time, a reliable preventative supplementation strategy should lessen the need for treatment of deficiency.

\section{Social justice perspective}

The recommendations for vitamin $\mathrm{D}$ rely on personal responsibility and it is questionable whether this is appropriate in populations with limited autonomy. Communitydwelling elderly and independent care home residents can purchase their own vitamin D supplements for personal use. However, people often move into care homes because they no longer have mobility or the mental capacity to live independently, and accordingly have more limited control over lifestyle decisions. Most elderly care home residents have some form of dementia. ${ }^{34}$ This results in a two-tier system, discriminating against those with the least cognitive independence. Even if residents or their family purchase OTC vitamin D supplements and request that these are administered by care staff, the GP still needs to approve their use. They would not be covered by homely remedy policies since these are limited to OTC products for short term treatment of minor ailments. ${ }^{31} 35$ The regulatory environment would make it difficult for elderly care homes to unilaterally decide to offer all residents daily vitamin $\mathrm{D}$ supplements, not least because residents are frequently registered with different GPs.

\section{Finance}

Even in a universal healthcare system such as the NHS, there are significant and often competing financial considerations for the different agencies involved in elderly care. The care home sector in England is fragmented with more than 15000 residential and nursing care homes operated by thousands of different providers. ${ }^{36}$ Depending on resident's circumstances, funding for places comes directly from residents and their families, local authorities, the NHS or charities. As highlighted by one of the participants, the involvement of GPs means 
care homes, residents or other funders do not need to purchase supplements. However, GP time is scarce and costly and using NHS prescribing as a vehicle for getting vitamin supplements to a sizeable at-risk population is a poor use of NHS resources. One year's supply of OTC vitamin D costs approximately $£ 15.00$ per person at typical high street prices. These costs could be absorbed into existing care home fees or covered by local authorities. A contrast is made with the provision of free vitamin D through the NHS Healthy Start scheme for children under 5 years in low income families on benefits, which some local authorities fund for all children. ${ }^{37}$ We believe equivalent arrangements should be in place for the frail elderly. This would enable care staff to be confident in the administration of such supplements and remove the need for medical prescribing and the associated cost.

\section{Formulation of vitamin D}

Vitamin D supplements can be formulated as tiny tablets, and are also available to be administered as drops, chewable and dispersible formulations which are easier to take than when combined with calcium. However, the additional burden to care staff of being required to administer a supplement in any form needs to be acknowledged. Using an appropriately fortified food stuff would shift the provisioning of vitamin D firmly to care homes as part of their food service. This would also eliminate the need for revising existing controls on medicines in care homes. However, the literature on the use of vitamin D fortified foods in the elderly is limited and the feasibility needs further research. 3839

\section{Nutritional well-being and the ethics of inaction}

Many frail elderly in the community suffer undernourishment. ${ }^{40}$ The move into a care home can improve nutrition as meals are provided and residents receive support with eating. Vitamin D needs to be part of this care. Other commentators in this journal have noted that policies and recommendations on vitamin $\mathrm{D}$ do not seem to be "taken seriously enough". ${ }^{4}$ The COVID-19 pandemic has brought conditions in care homes into the public eye and on to the political agenda. While practices in care homes are in the spotlight there is an urgent need for action to ensure vitamin $\mathrm{D}$ recommendations can be applied in care homes.

\section{Limitations of the study}

While this study provides insight into some of the underlying reasons why care home residents tend not to receive preventative vitamin D supplements, it is a small study and practices may be different in other areas. To improve the generalisability, we used purposive sampling in two nonneighbouring areas of southern England, and included stakeholders employed by a range of organisations. The fact that participants referred to national policy drivers as key determinants of current practice suggests the finding may be generalisable more widely in England. The literature suggests that the core issue of medicalisation of vitamin D may be relevant across the care sector in other countries. ${ }^{18}$

\section{CONCLUSION}

Daily vitamin D supplements are recommended for the entire UK population and the public are expected to obtain them as OTC supplements from pharmacies and other retailers. ${ }^{7}$ Residents of elderly care homes are particularly at risk of vitamin D deficiency but have limited ability to make lifestyle decisions of this kind. This study highlights that a gap exists between public health guidance and practice around vitamin D supplementation in the care sector: the professionals involved in the care of elderly residents perceive vitamin $\mathrm{D}$ as a medicine rather than a food. This means not enough elderly care home residents receive vitamin D supplements. As a result, their vitamin D levels remain low and they are at increased risk of falls and poor muscle strength and function. ${ }^{7}$ Evidence on possible links with vitamin D status and COVID-19 is currently inconclusive, ${ }^{12}$ but this should not detract from addressing a system which neglects the nutritional well-being of a group vulnerable to COVID-19.

Vitamin D in care homes needs further attention with mechanisms developed for the administration of low-risk dietary supplements or fortified foods by care staff. This will help us to progress from a situation where care staff feel constrained and vulnerable, to one where they are supported to improve the health of those in their care. For a universal, population-based approach, vitamin D supplementation at protective levels needs a professional separation from medicine and reframing as a matter of public health nutrition.

\section{Twitter Carol Williams @carowilluk}

Acknowledgements The study was conducted as part fulfilment of JW's MSc Public Health at Brighton and Sussex Medical School. The authors would like to acknowledge Catherine Aiken of School of Health Sciences, University of Brighton for comments and support on writing for this publication, and all the study participants for their time and contribution.

Contributors JW: conceptualisation, planning and data collection, transcription, analysis and manuscript writing. CW (not related): conceptualisation, analysis and manuscript writing. Both authors approved the final version of the manuscript.

Funding The authors have not declared a specific grant for this research from any funding agency in the public, commercial or not-for-profit sectors.

Competing interests None declared.

Patient consent for publication Not required.

Ethics approval This study was approved by the University of Brighton, School of Health Sciences Research Ethics and Governance Panel, February 2018.

Provenance and peer review Not commissioned; externally peer reviewed.

Data availability statement Data are stored in a private repository. Redacted data to ensure anonymity are available on reasonable request.

Open access This is an open access article distributed in accordance with the Creative Commons Attribution Non Commercial (CC BY-NC 4.0) license, which permits others to distribute, remix, adapt, build upon this work non-commercially, and license their derivative works on different terms, provided the original work is properly cited, appropriate credit is given, any changes made indicated, and the use is non-commercial. See: http://creativecommons.org/licenses/by-nc/4.0/. 
ORCID iD

Carol Williams http://orcid.org/0000-0003-1735-2523

\section{REFERENCES}

1 Acheson ED. Public health in England. The report of the Committee of Inquiry into the future development of the public health function 1988.

2 Gordon AL, Goodman C, Achterberg W, et al. Commentary: COVID in care homes - challenges and dilemmas in healthcare delivery. Age Ageing 2020;49:701-5.

3 Lanham-New SA, Webb AR, Cashman KD, et al. Vitamin D and SARS-CoV-2 virus/COVID-19 disease. BMJNPH 2020;3:106-10.

4 Kohlmeier M. Avoidance of vitamin D deficiency to slow the COVID-19 pandemic. BMJNPH 2020;3:67-73.

5 Nair R, Maseeh A. Vitamin D: The "sunshine" vitamin. J Pharmacol Pharmacother 2012;3:118-26

6 Spiro A, Buttriss JL. Vitamin D: an overview of vitamin D status and intake in Europe. Nutr Bull 2014;39:322-50.

7 SACN (Scientific Advisory Committee on Nutrition). Vitamin D and health. London, 2016. Available: https://www.gov.uk/government/ publications/sacn-vitamin-d-and-health-report

8 PHE (Public Health England). COVID-19: understanding the impact of COVID-19 on BAME communities, 2020. Available: https://www.gov. uk/government/publications/covid-19-understanding-the-impact-onbame-communities

9 Mitchell F. Vitamin-D and COVID-19: do deficient risk a poorer outcome? Lancet Diabetes Endocrinol 2020;8:570.

10 Martineau AR, Forouhi NG. Vitamin D for COVID-19: a case to answer? Lancet Diabetes Endocrinol 2020;8:735-6.

11 Grant WB, Lahore H, McDonnell SL, et al. Evidence that vitamin D supplementation could reduce risk of influenza and COVID-19 infections and deaths. Nutrients 2020;12:988.

12 NICE (National Institute for Health and Care Excellence). Vitamin D for COVID-19: evidence review, 2020. Available: https://www.nice. org.uk/advice/es28/evidence

13 SACN (Scientific Advisory Committee on Nutrition). Vitamin D and acute respiratory infections: rapid review, 2020. Available: https://www.gov.uk/ government/groups/scientific-advisory-committee-on-nutrition

14 NHS England. Vitamin D (corona virus update), 2020. Available: https://www.nhs.uk/conditions/vitamins-and-minerals/vitamin-d/ [Accessed 12 Aug 2020].

15 COMA (Committee of Medical Aspects of Food Policy). The nutrition of elderly people. London: HMSO, 1992.

16 SACN (Scientific Advisory Committee on Nutrition). Update on vitamin D : position statement, 2007. Available: https://www.gov.uk/ government/publications/sacn-update-on-vitamin-d-2007

17 PHE (Public Health England). PHE publishes new advice on Vitamin D [Internet], 2016. Available: https://www.gov.uk/government/news/ phe-publishes-new-advice-on-vitamin-d [Accessed 8 Sep 2020].

18 Rolland Y, de Souto Barreto P, van Kan GA, et al. Vitamin D supplementation in older adults: searching for specific guidelines in nursing homes. J Nutr Health Aging 2013;17:402-12.

19 NHMRC (Australian National Health and Medical Research Council). Nutrient reference values for Australia and New Zealand: Commonwealth of Australia, 2006. Available: http://www.nhmrc.gov.au

20 Pilz S, Zittermann A, Trummer C, et al. Vitamin D testing and treatment: a narrative review of current evidence. Endocr Connect 2019;8:R27-43.

21 Verhoeven V, Vanpuyenbroeck K, Lopez-Hartmann M, et al. Walk on the sunny side of life-epidemiology of hypovitaminosis $D$ and mental health in elderly nursing home residents. J Nutr Health Aging 2012;16:417-20.

22 Diekmann R, Winning K, Bauer JM, et al. Vitamin D status and physical function in nursing home residents: a 1-year observational study. Z Gerontol Geriatr 2013;46:403-9.
23 Samefors M, Östgren CJ, Mölstad S, et al. Vitamin D deficiency in elderly people in Swedish nursing homes is associated with increased mortality. Eur J Endocrinol 2014;170:667-75.

24 MacDonell SO, Miller JC, Harper MJ, et al. Vitamin D status and its predictors in New Zealand aged-care residents eligible for a government-funded universal vitamin D supplementation programme. Public Health Nutr 2016;19:3349-60.

25 Codex (Codex Alimentarius Commission). Guidelines on vitamin and mineral food supplements: Food and Agriculture Organisation, 2005. Available: http://www.fao.org/fao-who-codexalimentarius/codextexts/guidelines/en/

26 European Parliment, Council of the European Union: DIRECTIVE 2002/46/EC. Commission Directon the approximation of the laws of the Member States relating to food supplements. Official Journal of the European Communities L 183, 12/07/2002 P. 0051 - 0057, 2002. Available: https://eur-lex.europa.eu/legal-content/ EN/ALL/?uri=celex\%3A32002L0046

27 USFDA (US Food and Drug Administration). Dietary supplements products and ingredients, 2020. Available: https://www.fda.gov/ food/dietary-supplements/dietary-supplement-products-ingredients [Accessed 16 Jul 2020]

28 Health and Social Care Act 2008 (Regulated Activities) Regulations 2014, STAT. 29362014

29 NHS England. Conditions for which over the counter items should not routinely be prescribed in primary care: guidance for CCGs, 2018. Available: https://www.england.nhs.uk/publication/ conditions-for-which-over-the-counter-items-should-not-routinelybe-prescribed-in-primary-care-guidance-for-ccgs/ [Accessed 8 Sep 2020].

30 Braun V, Clarke V. Using thematic analysis in psychology. Qual Res Psychol 2006;3:77-101.

31 CQC (Care Quality Commission). Over the counter medicines and homely remedies, 2020. Available: https://www.cqc.org.uk/guidanceproviders/adult-social-care/over-counter-medicines-homelyremedies [Accessed 8 Sep 2020].

32 NICE (National Institute for Health and Care Excellence). Vitamin D: supplement use in specific population groups. PH56, 2014 Available: https://www.nice.org.uk/guidance/ph56 [Accessed 8 Sep 2020].

33 PHE (Public Health England). Healthier and more sustainable catering. A toolkit for serving food to older people in residential care [internet], 2017. Available: https://www.gov.uk/government/ publications/healthier-and-more-sustainable-catering-a-toolkit-forserving-food-to-adults

34 Matthews FE, Arthur A, Barnes LE, et al. A two-decade comparison of prevalence of dementia in individuals aged 65 years and older from three geographical areas of England: results of the cognitive function and ageing study I and II. Lancet 2013;382:1405-12.

35 NICE (National Institute for Health and Care Excellence). Managing medicines in care homes. 2014 (Social care guideline [SC1]).

36 CQC (Care Quality Commission). The state of health care and adults social care in England 2018/19, 2019. Available: www.gov.uk/officialdocuments

37 Moy RJ, McGee E, Debelle GD, et al. Successful public health action to reduce the incidence of symptomatic vitamin $D$ deficiency. Arch Dis Child 2012:97:952-4.

38 Itkonen S, Erkkola M, Lamberg-Allardt C. Vitamin D fortification of fluid milk products and their contribution to vitamin D intake and vitamin D status in observational studies - a review. Nutrients 2018;10:1054-3.

39 Keane EM, Healy M, O'Moore R, et al. Vitamin D-fortified liquid milk: benefits for the elderly community-based population. Calcif Tissue Int 1998;62:300-2.

40 MTF (Malnutrition Task Force). State of the nation: older people and malnutrition in the UK today, 2017. Available: https://www.malnutri tiontaskforce.org.uk/ [Accessed 12 Aug 2020]. 